\title{
A implantação da Usina Hidrelétrica de Jirau no rio Madeira e os processos de desterritorialização em Rondônia
}

\author{
El despliegue de la planta hidroeléctrica de Jirau en el río Madeira y los \\ procesos de desterritorialización en Rondônia
}

\section{The deployment of Jirau hydroelectric plant on the Madeira river and the processes of deterritorialization in Rondônia, Brazil}

\author{
Paula Stolerman \\ paulastolerman.ps@gmail.com \\ Mestre em Geografia pela UNIR e Membro do GEPCULTURA
}

Sheila Castro dos Santos

sheila1705@gmail.com

Doutoranda em Geografia UFPR

Adnilson de Almeida Silva

adnilsonn@gmail.com

Professor Doutor do GEPCULTURA da UNIR

Nicolas Floriani

florianico@gmail.com

Professor Doutor do Programa de Pós-graduação em Geografia da UEPG

Resumo: Este trabalho surge em decorrência da implantação da Usina Hidrelétrica (UHE) Jirau, no rio Madeira, em Rondônia, onde parte da população do Distrito de Mutum-Paraná, no Município de Porto Velho, foi remanejada para Nova Mutum, pelo Consórcio Energia Sustentável do Brasil (ESBR). Este remanejamento ocorreu com divergências de ambas as partes: de um lado o consórcio não cumpriu com algumas de suas negociações e de outro os moradores insatisfeitos procuraram reconstruir sua territorialidade no novo espaço que lhes foi imputado. A alternativa então foi o "auto reassentamento" dos moradores de Mutum-Paraná na localidade de Jirau. O rápido crescimento demográfico da localidade de Jirau é fruto da resistência prolongada dos atingidos que não encontram meios para reconstituir o seu modo de vida anterior ao remanejamento.

Palavras-chave: Hidrelétrica. Desterritorialização. Resistência. Rondônia.

Resumen: El presente artículo es debido a la implementación de la central hidroeléctrica de Jirau (HPP), en el río Madeira en Rondonia, donde parte de la población del distrito de Mutum-Paraná, en el municipio de Porto Velho, fue reasignado a Nova Mutum, por la compañía Energia Sustentável do Brasil (ESBR). Este traslado se llevó a cabo con las diferencias de ambas partes, por el contrario el consorcio que se ha podido cumplir con algunos de sus negociaciones y otros descontentos residentes que buscaban reconstruir 
su territorialidad en el nuevo espacio que se ha asignado. La alternativa era entonces el "restablecimiento automático" de los residentes de Mutum-Paraná en la localidad de Jirau. El crecimiento acelerado de la población de la localidad de Jirau es que el resultado de la prolongada resistencia de la presa de afectados que no encuentran maneras de reconstruir su forma de vida antes de la reubicación.

Palabras-Clave: Hidroeléctrica. Desterritorialización. Resistência. Rondônia.

\begin{abstract}
This paper comes due to the deployment of the hydropower plant (HPP) Jirau, on the Madeira River in Rondonia (Amazon) where part of the population of the District of Mutum-Paraná, in the municipality of Porto Velho, was reassigned to Nova Mutum by the town company Energia Sustentável do Brasil (ESBR). This relocation carried out with divergences of both parts: the consortium has failed to comply some of its negotiations and disgruntled residents who sought to rebuild its territoriality in the new imputed space. The alternative then was the "self-resettlement" of the residents of Mutum-Paraná in the locality of Jirau. The rapid population growth of Jirau is the result of prolonged resistance of dam affected who do not find ways to reconstruct their way of life prior to the relocation.
\end{abstract}

Keywords: Hydroelectric. Deterritorialization. Resistance. Rondônia.

\title{
CONSIDERAÇÕES INICIAIS
}

Durante o percurso da ocupação portuguesa no espaço hoje denominado de Amazônia, ocorreram diversas frentes migratórias que utilizavam os rios como meio de transporte e manutenção da vida, pois era deles que se retirava o necessário para o sustento familiar. Grupos sociais estabelecidos em decorrência destas intervenções para a exploração e ocupação do território muitas vezes se combinaram à populações indígenas e formaram comunidades conhecidas atualmente como populações tradicionais.

Para além destes grupos, as práticas de uso e exploração comum dos recursos ambientais, como as águas dos rios foram realizada na Amazônia, sendo que em nosso cotidiano, houve alterações desse modelo e as construções de complexos hidrelétricos tornaram-se parte da realidade da Amazônia brasileira.

As migrações compulsórias tornaram-se um fator recorrente do modelo atual do capitalismo pós-fordista ou flexível, causando uma série de impactos sociais, ambientais, políticos e econômicos. A incrível necessidade de conquistar novos espaços para o acúmulo de capital se move para as "fronteiras de expansão", espaços considerados ainda não devidamente capitalizados, como é o caso da Amazônia, transmutando em uma vitrine do que Costa intitula de

[...] "modernização arrasadora" que impõe sua geometria regular sobre todos os espaços: estradas que parecem retas sem fim, gigantescos quadriláteros de novos loteamentos e conjuntos habitacionais padronizados, imensos círculos das áreas irrigadas pelo sistema de pivôs centrais [...]. (COSTA (2011, p.166).

Consubstanciando essa afirmativa, adicionamos a contribuição dos projetos hidrelétricos atualmente impostos à Amazônia para a contabilidade de "aglomerados 
de exclusão" (HAESBAERT, 2011) formados pelo deslocamento de pessoas que antes viviam em um lugar engolido pela represa.

Esse é o caso da construção da Usina Hidrelétrica (UHE) de Jirau, no rio Madeira, Estado de Rondônia, cujo sentido atende aos interesses econômicos e políticos, ainda que para tanto propicie a exclusão social e ambiental, causando impactos de diversas ordens para as populações ribeirinhas e indígenas da área de influência do empreendimento hidrelétrico.

Um dos pensamentos dos cidadãos é que o Estado deveria ser um órgão não só delimitador de ações sociais, com medidas de políticas públicas, mas que também pudesse ser atuante por meio do Ministério Público (MP) para proteger os direitos desse mesmo cidadão, quando este fosse coagido pelo Estado a tomar decisões que possam ferir a sua integridade psicológica. No entanto, o que notamos nas comunidades atingidas pelos empreendimentos do Complexo Hidrelétrico do Madeira é a contradição deste direito. Pois, o MP como outros órgãos governamentais não conseguiram atuar na proteção dos direitos do cidadão.

Após algumas entidades e movimentos sociais entrarem com pedidos para interferência judicial nas ações das empresas responsáveis pela construção da UHE Jirau que degradavam trabalhadores e populações atingidas pelo projeto hidrelétrico, o MP passou a desenvolver ações organizadas e a questionar posições tomadas pelo Consórcio Energia Sustentável do Brasil (ESBR) devido não executar ações mitigadoras previstas, que em alguns casos deixaram de ser cumpridas. Todavia, as ações judiciais que estão ocorrendo ainda não possuem uma consolidação do direito do cidadão e a maior parte dos atingidos não conseguem coletivamente se organizar.

\section{ABORDAGENS TEÓRICAS E AS IMPLICAÇÕES POLÍTICAS}

A compreensão sobre a implantação do Complexo Hidrelétrico do Madeira, do qual a Usina de Jirau é integrante, só pode ser vista em sua plenitude a partir do papel exercido pelo Estado que busca atender interesses coletivos e dos atores detentores de poder econômico.

Nesta discussão, o poder do Estado na equiparação de um conjunto de instituições e de aparelhos que garantem a sujeição dos cidadãos a um poder estatal determinado, encontra o sentido dado por Raffestin (1993, p.53) ao inferir que: "O poder com uma letra maiúscula postula, como dados iniciais, a soberania do Estado, a forma da lei ou da unidade global de uma dominação; essas não são mais que formas terminais".

Em direção semelhante sobre o sentido de poder, Foucault $(1985 ; 1987 ; 2012)$ busca evidenciar e elabora algumas proposições que poderiam definir a natureza desta palavra. Sua primeira definição foi que o poder pode ser exercido a partir de diversos pontos, sendo que as relações de poder não estão em posição de exterioridade no que diz respeito a outros tipos de relações (econômicas, sociais etc.), mas são imanentes a eles. Pois o poder coage quem está em baixo de seu domínio; não há uma oposição binária e global entre 
dominador e dominados. As relações de poder são, concomitantemente, intencionais e não subjetivas. E, onde há poder há resistência, contudo, esta jamais se encontra em posição de exterioridade em relação ao poder.

Mediante essa constatação relacional, verifica-se que para o exercício é indispensável a existência de variáveis que estão intimamente interligadas e se comportam de formas indissociáveis, as quais se expressam e legitimam o espaço/território, conforme afirma Raffestin:

[...] em qualquer relação, torna-se inútil distinguir um poder político, econômico, cultural etc. sendo toda relação um lugar de poder, isso significa que o poder está ligado muito intimamente à manipulação dos fluxos que atravessam e desligam a relação, a saber, a energia e a informação. (...) A troca verbal, a relação oral, não é puramente informacional, pois é necessário uma quantidade de energia para que a comunicação tenha lugar. O laço entre o poder e o saber é evidente, mas não há nem informação pura nem energia pura. Trata-se sempre de uma combinação das duas. O espaço-tempo relacional é organizado pela combinação de energia e informação. (RAFFESTIN, 1993, p.54).

Ora a política, na sua configuração recente e restrita, tem a conotação de política pública a qual engloba ações sociais. O aparecimento desse novo ramo se deu quando pesquisadores procuraram entender a dinâmica das relações entre governos e cidadãos, extrapolando a estrita ligação das tradicionais dimensões normativas e morais que diz respeito ao funcionamento de instituições específicas.

No caso particular de nossa análise, constata-se que após a grande campanha de marketing feita pelo Estado por meio das mídias e do setor privado, houve em Porto Velho (RO) um envolvimento de pessoas pró-usinas, via-se outdoors e propagandas com rostos conhecidos pela sociedade em geral como garotos-propaganda do empreendimento, ainda que muitos desses não possuíssem a exata dimensão de seus desdobramentos para a sociedade rondoniense.

A vinda do ex-presidente da República, Luiz Inácio Lula da Silva, para dinamizar as obras e por último no ano de 2011 a visita da atual Presidente Dilma Rousseff, exemplificaram o programa de ações para incentivar as obras do Programa de Aceleração do Crescimento - PAC, no qual o Complexo Hidrelétrico do Madeira integra.

É necessário destacar que o empreendimento hidrelétrico faz parte do conjunto de estratégias da Integração da Infraestrutura Regional Sul-Americana - IIRSA, cujo objetivo consiste na modernização da infraestrutura de transporte, energia e telecomunicações, mediante ações conjuntas, de modo a estimular a integração política, econômica, sociocultural da América do Sul. Esse fato por si só explica que o empreendimento hidrelétrico, de certo modo, servirá para atender interesses que perpassam o território nacional, dentro do contexto da globalização.

Assim, seguindo o procedimento regulamentado que antecede o início das obras, foram programadas e realizadas quatro audiências públicas com a participação de diversos segmentos da sociedade. Contudo, o número dos cidadãos presentes nestas audiências, 
em contraposição a quantidade de moradores de Porto Velho chega a ser de uma diferença absurda, sendo a maior parte dos participantes representantes das comunidades a serem atingidas imediatamente, bem como de dirigentes de organizações não governamentais, professores universitários, pessoas envolvidas em partidos políticos e colaboradores das empresas que buscavam explicar o funcionamento do empreendimento hidrelétrico.

Nas vezes que foram a público abordar sobre o Complexo Hidrelétrico do Madeira, os gestores públicos estaduais e municipais rondonienses incentivaram a implementação da obra e demonstraram o quão agraciado Rondônia seria com a construção das barragens em seu espaço, como pode ser visto nas afirmações a seguir:

"Este é o melhor momento da história de Porto Velho" [...] “Há um sentimento muito positivo na cidade, uma expectativa de dias melhores, com mais qualidade de vida, emprego e inclusão social. E isso com base numa sistemática de discussão exemplar. O diálogo é transparente e existe o debate popular" (Roberto Eduardo Sobrinho - exPrefeito de Porto Velho, 2007).

“Será preciso antecipar soluções. É preciso priorizar a parte social. Com a realização da obra, as demandas por educação, saúde e segurança vão aumentar, será necessário aprimorar a infraestrutura de Porto Velho. A capacitação de trabalhadores, incluindo as mulheres, tem de ser outra prioridade. (...) O Brasil tem necessidade de energia e esta obra é uma contribuição de Rondônia para o Brasil. Temos de aproveitar o nosso potencial energético, precisamos ser inteligentes e utilizar nossas riquezas da maneira certa" (Ivo Narciso Cassol, ex-Governador de Rondônia, 2007 apud http://www. odebrechtonline.com.br/materias/01501-01600/1559/).

Enquanto em Porto Velho a população ainda espera o milagre da urbanização, na capital federal no dia 12 de junho de 2008, foi assinado o contrato de concessão da UHE Jirau, com a presença do ex-Presidente Luiz Inácio Lula da Silva e da ex-Ministra-Chefe da Casa Civil, Dilma Rousseff. Na ocasião o Diretor-Presidente do Consórcio Madeira Energia S.A. (Mesa - atualmente ESBR), Irineu Meireles, afirmou que:

[...] a concessionária nasceu comprometida com o desenvolvimento sustentável, “observando irrestritamente a promessa de preservação e proteção ambiental de Rondônia e da Floresta Amazônica". E acrescentou: "Vamos implementar um modelo de usina hidrelétrica totalmente inovador, no qual provaremos que o retorno financeiro, o respeito ao meio ambiente e a consciência social podem e devem andar de mãos dadas nos projetos de infraestrutura de grande porte, tão necessários para o crescimento da nossa economia, capitaneado pelo PAC". (http://www.odebrechtonline.com.br/ materias/01501-01600/1559/. Acessado em: 20 dez. 2013).

Com esse discurso soberbo, realmente o empreendimento dos sonhos foi concretizado, entretanto, várias problemáticas se apresentam atualmente, colocando em xeque as garantias quanto às certezas dos impactos: a) na estrutura do rio Madeira que ainda está em formação conduzindo seus sedimentos cada ano para lugar diferente; $b$ ) não é possível mensurar o impacto ecológico que teremos com o passar do tempo; c) o 
grandioso impacto sociocultural dentro das áreas atingidas pelas barragens e das áreas de influência direta e indireta do empreendimento.

Entre as problemáticas de ordem social, direta e indireta encontram-se: a) o aumento de estupro; b) índice de prostituição crescente; c) aumento de acidentes de automóveis; d) uma infraestrutura urbana inferior à prometida; e) aumento dos índices de violência, entre tantas outras que minoram a qualidade de vida da população. Reafirmamos que os impactos gerais ainda não podem ser totalmente mensurados, pois o empreendimento está em fase final de execução, mas apresentamos os percentuais sobre o município de Porto Velho e o Distrito de Jaci-Paraná, conforme Possamaí, citado por Lima e Vasconcelos:

Porto Velho, de 2008 a 2010, teve sua população acrescida em 12,5\%, com um aumento da taxa de homicídios dolosos em 44\%. Jaci-Paraná, distrito de Porto Velho mais próximo aos canteiros de obras, teve um aumento no registro de estupros na ordem de 76,8\%, no mesmo período. (LIMA; VASCONCELOS, 2013, p. 183).

No aprofundamento dessas questões, Amaral, Almeida Silva e Leandro, situam e constatam que:

[...] A realidade, como cenário, é que [...] por conta desses empreendimentos propiciam uma série de desdobramentos, nas quais nem o poder público, nem a sociedade rondoniense conseguem as demandas como: saúde, educação, transporte, segurança, o que resulta num quadro de instabilidades [...] precárias condições de moradia, dificuldade no acesso a políticas públicas. (AMARAL; ALMEIDA SILVA; LEANDRO, 2011, p.32).

Essas situações e condições conduzem-nos à reflexão de Milton Santos (2011) quando trata sobre a ordem trazida pelos vetores da hegemonia que cria, localmente, desordem, não apenas porque conduz a mudanças funcionais e estruturais, mas, sobretudo porque essa ordem não é portadora de um sentido, já que o seu objetivo - o mercado global, por isso ao ser executada dessa maneira a globalização tem uma forma "perversa para a maioria da Humanidade".

As barragens promovem uma série de cortes no espaço vivido e criam paisagens que atendem ao projeto utilitarista coroado pelo pensamento de Francis Bacon, conforme descreve Shiva (2001, p.304): "a criação da noção de um instituto de pesquisa moderno, e da visão das ciências industriais como uma fonte de poder econômico e político". Para esta perspectiva metodológica, apresentada como neutra e racional baseada no controle e repetição de experiências que manipulavam os processos da natureza, implicava na separação entre homem e mulher, humanidade e natureza, objetivo e subjetivo.

Esta visão racionalista-utilitarista dos recursos naturais e territoriais ainda rege os processos decisórios e as políticas de gestão e aproveitamento dos rios pelo Estado brasileiro, em detrimento do uso diferenciado dos recursos naturais pelos grupos e povos que vivem na floresta. $\mathrm{O}$ uso social das comunidades ${ }^{1}$ ribeirinhas está galgado em um

\footnotetext{
${ }^{1}$ Por comunidade, Weber (2002, p.71) denomina como "uma relação social [...] em que a orientação da ação social [...] baseia-se em um sentido de solidariedade: o resultado de ligações emocionais ou tradicionais dos participantes".
} 
conjunto de saberes tradicionais que não estão condicionados às compartimentações das ciências hegemônicas especializadas, devido à sua referência tanto à materialidade dos processos e comportamentos naturais, quanto à dimensão simbólica dos referidos processos. (LEONEL JÚNIOR, 1998, p.220).

As contestações ao modelo predatório de apreensão da natureza pelo capitalismo geraram críticas solidamente construídas e empiricamente comprovadas e a partir da década de 1970, as sociedades ocidentais passaram a regulamentar e controlar mais precisamente os encargos impostos ao ambiente pela industrialização. (HANNIGAN, 2009). Seguindo a padronização imposta pelos países centrais, o Brasil institui a apresentação de Estudos de Impacto Ambiental e Relatórios de Impacto Ambiental para a instalação de usinas hidrelétricas pela Resolução do CONAMA Nº 001, de 23 de janeiro de 1986.

Fica exposta então, a produção de certo consenso nos diversos campos do espaço social², tais como: acadêmico, jurídico ou mesmo econômico, a respeito das consequências negativas, ambientais e sociais, decorrentes do fechamento dos lagos formados por usinas hidrelétricas. Isto fica aparente quando é estabelecida uma série de normas e implicações jurídicas que devem ser devidamente atendidas em conformidade com a legislação competente e que deveriam garantir a redução das perdas socioambientais a um mínimo.

Entre os instrumentos presentes na legislação, encontra-se o processo de Licenciamento de Projetos hidrelétricos. Estes devem atender a uma série de normas, como a formulação dos EIA/RIMA. No entanto, esses relatórios embora contestados por organizações da sociedade civil e ambientalistas por não refletirem na maioria dos casos as especificidades dos territórios onde se instalam estes projetos. Empiricamente, a história dos projetos hidrelétricos vem acumulando desastres ambientais e perdas que resultam na impossibilidade de grupos sociais reconstruírem seus modos de vida no espaço.

Desta forma, percebemos que antes de tratar-se da aplicação de políticas compensatórias ou de redução de perdas ambientais ou sociais, há na prática uma disjunção entre as esferas ambiental e social nos projetos promovidos pelo Estado brasileiro visando o desenvolvimento econômico do país, como se houvesse a possibilidade de considerar uma destas implicações sem recorrer à outra.

Nesta perspectiva onde o socioambiental é fracionado em programas de compensação ambiental e social, são garantidas aos consórcios construtores as licenças que permitem a construção das barragens. Não ocorreu de forma diferente no processo que levou à instalação dos canteiros de obras das UHEs Santo Antônio e UHE Jirau - essas são chamadas por Monteiro (2012) como "hidrelétricas malditas", em razão dos inúmeros problemas e impactos causados.

[...] “O atual modelo perverso de desenvolvimento é balizado pela demanda de energia imposta por grupos econômicos poderosos. Para justificar os mega projetos de

\footnotetext{
${ }^{2}$ Conforme Buttimer (1982, p.180): “O espaço tem sido visto como recipiente de populações com características demográficas particulares e como estágio no qual se situam as redes de interação social. Na perspectiva de Bourdieu (1989) não se trata de compreender a sociedade como um conceito generalizante, mas sim como a composição de campo social. Os campos sociais são as esferas que agrupam os agentes em disputa pelo poder material e simbólico inscritos aos mesmos.
} 
hidrelétricas na Amazônia, o governo brasileiro, em coro e parceria com grandes empresas internacionais, costuma usar chavões do tipo "energia renovável" ou "benção divina". [...] Populações tradicionais, então, veem seus costumes, culturas, direito à terra ancestral, ameaçados para suprir as necessidades de consumo desvairados criadas pelas elites do hemisfério norte". [...] As tomadas de decisão por parte do poder público, infelizmente, acontecem antes que se tenha esse conhecimento ou da possibilidade da compreensão global dos processos em que elementos negativos interagem e podem levar à "débâcle" étnica. (MONTEIRO, 2010, p.84).

No caso da barragem de Jirau, esse processo ocorreu devido à pressão do Governo Federal para a liberação da obra pelo IBAMA. Foi criada, em oposição à legislação vigente, uma licença parcial, que permitiu a construção do canteiro de obras e ensecadeira.

Este trabalho vem refletir a respeito dos processos que destroem e recriam territórios materiais e simbólicos, tendo como aporte o trabalho de campo realizado em 2012, junto à comunidade que migrou para a localidade de Jirau em decorrência da destruição do Distrito Mutum-Paraná, após o início das obras de construção do empreendimento hidrelétrico.

\section{PROCESSOS DE DESTERRITORIALIZAÇÃO E RETERRITORIALIZAÇÃO NO CONTEXTO DA CONSTRUÇÃO DA UHE JIRAU}

Uma das consequências dos barramentos de rios são os deslocamentos compulsórios de grupos que edificaram sua cultura e identidade atrelada ao território em sentido tanto material quanto simbólico. No presente trabalho partilhamos do conceito de território exposto por Guattari e Rolnik, citados por Costa e Bruce (2002).

A noção de território aqui é entendida num sentido muito amplo, que ultrapassa o uso que fazem dele a etologia e a etnologia. Os seres existentes se organizam segundo territórios que os delimitam e os articulam aos outros existentes e aos fluxos cósmicos. O território pode ser relativo tanto a um espaço vivido, quanto a um sistema percebido no seio da qual um sujeito se sente "em casa". O território é sinônimo de apropriação, de subjetivação fechada sobre si mesma. Ele é o conjunto de projetos e representações nos quais vai desembocar, pragmaticamente, toda uma série de comportamentos, de investimentos, nos tempos e nos, espaços sociais, culturais, estéticos, cognitivos. (COSTA; BRUCE, 2002, p.6).

Ao tratarmos sobre a UHE Jirau, verificamos que o Movimento dos Atingidos por Barragens - MAB, associados a organizações não governamentais e universidades, reiteram em suas lutas a visibilidade das comunidades que saindo dos territórios onde reproduziam seus modos de vida tem sua existência anulada. Logo, o território pode ser relativo tanto a um espaço vivido, quanto a um sistema percebido no seio da qual um sujeito se sente "em casa".

Devido à construção da UHE Jirau, houve a necessidade de remanejar todas as pessoas que viviam no Distrito de Mutum-Paraná, por este estar integralmente inserido no 
que é chamado de área de influência direta da barragem (AID) pelo consórcio construtor, o que acarretou no total alagamento de seu perímetro. Para os moradores de MutumParaná impuseram três possibilidades de remanejamento: o reassentamento urbano, o reassentamento rural ou a indenização.

A migração compulsória, característica da implantação de grandes barragens, implica em um processo de desterritorialização, que "pode ser tanto simbólico, com a destruição de símbolos, marcos históricos, identidades, quanto concreto, material-político e/ou econômico, pela destruição de antigos laços/fronteiras econômico-políticos de integração." (COSTA, 2011 p. 181).

Todas as edificações da antiga comunidade de Mutum-Paraná foram completamente destruídas. No primeiro semestre do ano de 2012 foi possível encontrar na localidade apenas vestígios de baldrames, pedaços de cercas e algumas partes de residências que os moradores não puderam ou não conseguiram transportar no processo de remanejamento.

Em decorrência do remanejamento, o território tem um novo sentido o qual abriga significados distintos daqueles que foram construídos durante o período de vida do Distrito de Mutum-Paraná. Os espaços em que se dava a reprodução social e simbólica da comunidade, agora são incorporados a formas sociais distintas da precedente, dentro da lógica dos grandes projetos governamentais que intervém nas formas tradicionais de organização do espaço e aproveitamento dos recursos territoriais, como é o caso da UHE Jirau. (ACSELRAD; SILVA, 2011).

Enquanto viveram em Mutum-Paraná, as pessoas exerciam o que é chamado de pluriatividades. Além de serviços fixos como nas madeireiras instaladas no Distrito de Mutum Paraná, a garimpagem, a pesca, o plantio nas várzeas e nos quintais a criação de animais. É importante elencar que mesmo aqueles que não tinham a pesca como sua principal fonte de renda praticavam-na para a subsistência e também como atividade de lazer, conforme constatamos em campo nos anos de 2009 e 2010.

Em dezembro de 2010 iniciaram os deslocamentos para Nova Mutum com os préstimos de empresas de mudanças que foram pagas pelo Consórcio ESBR ${ }^{3}$. Após alguns meses estivemos em contato com estes moradores já devidamente instalados em suas novas moradias. Em Mutum-Paraná as casas eram de madeira, em Nova Mutum todas as residências foram feitas com blocos de concreto armado, que são encaixados no local onde se fixaram as residências.

A nova cidade foi construída com o apoio logístico aos trabalhadores do Consórcio ESBR, em um modelo que podemos chamar Company Town, mas foi apresentada aos moradores advindos de Mutum Paraná como um projeto urbanístico que atenderia às suas necessidades materiais, emocionais e simbólicas ${ }^{4}$. Por Company Town, suas estruturas são descritas por Rodrigues como:

[...] modelos aplicados, significam a reconstrução do fenômeno urbano por meio da negação das estruturas existentes (cidades "espontâneas") e fundação de novas

\footnotetext{
${ }^{3}$ Informação em Jirau Notícias Edição no 10 dezembro de 2010/janeiro de 2011.

${ }^{4} \mathrm{Na}$ entrada da nova cidade é possível observar um outdoor com os dizeres: "Nova Mutum: preparada para ser feliz".
} 
estruturas, voltando seus objetivos e "conteúdos" para a viabilização econômica dos empreendimentos a que estão vinculadas, utilizando a "forma" urbana, por meio do projeto, enquanto um dos instrumentos deste fim. (RODRIGUES, 2002, p.117).

Nova Mutum é caracterizada pela trama urbana criada artificialmente (NOGUEIRA, 2010) para atender aos funcionários do Consórcio ESBR e que se diferencia das formas regulares de urbanização, consolidando um novo espaço geográfico, alheio às representações culturais dos antigos moradores remanejados de Mutum-Paraná - para os quais só restaram as lembranças de seu local de origem.

O que ocorreu foi que devido à inadequação do remanejamento às necessidades materiais e simbólicas da comunidade de Mutum-Paraná, muitas famílias abandonaram suas casas no núcleo urbano da nova cidade e então se deslocaram para Jirau, uma localidade às margens da BR 364 - distante aproximadamente cem quilômetros de Porto Velho - e que ainda guarda algumas semelhanças com a paisagem cultural construída no antigo Distrito.

O remanejamento para Nova Mutum não atendeu às necessidades dos moradores do antigo Distrito, agora submerso pela barragem de Jirau. Alheia aos processos sociais que garantem a construção e significação dos territórios, Nova Mutum figura como um conjunto de edificações artificiais, onde os remanejados não são sujeitos da construção de seu espaço.

Desta maneira, essas pessoas em busca de um território idealizado, que permitam dar continuidade ao seu modo de vida e promovem a dialética que permite a destruição/ recriação de territórios na contemporaneidade visto que

Diante da massa de despossuídos do planeta, em índices de desigualdade social e de exclusão cada vez mais violentos, o "apegar-se à terra", a reterritorialização é um processo que vem ganhando força. Ele se torna imprescindível não somente como fonte de recursos para a sobrevivência física cotidiana mas também para a recriação de seus mitos, de suas divindades ou mesmo para manter viva a memória de seus mortos. (COSTA, 1999, p.185).

Para se compreender melhor as percepções dos moradores a respeito do território e do processo desterritorialização/reterritorialização foram realizadas durante pesquisa de campo na localidade Jirau, entrevistas semiestruturadas, as quais são reproduzidas alguns de seus trechos mais significativos para compreender a realidade encontrada.

Desse modo, evidenciamos as percepções e sentimentos dos remanejados em relação ao seu território recentemente construído por meio de seu discurso, cuja transcrição e interpretação de alguns trechos dos enunciados realizados pelos moradores permitiram explicitar várias das reações demonstradas pelos sujeitos reterritorializados, as quais se referem a sua experiência material e simbólica no território. As enunciações consistem-se como atividades discursivas, e delas podem-se extrair as "condições históricas, registrando o lugar socioideológico no qual o sujeito se posiciona." (SILVA, 2009, p. 99).

As impressões que surgiram das conversas com os atuais moradores de Jirau e que foram remanejados de Mutum-Paraná e indicam uma relação entre o deslocamento dessa 
população para a nova localidade e a memória que constituiu a territorialidade do antigo local de moradia. O rápido crescimento demográfico da localidade de Jirau, situada a poucos quilômetros do reservatório da UHE, às margens da BR 364, é fruto da resistência prolongada dos atingidos pela sua construção, remanejados para Nova Mutum, e que não encontram meios para reconstituir seu modo de vida anterior.

Enquanto Mutum-Paraná existiu, a população podia ver e conviver com os trilhos e caixa d'água da Estrada de Ferro Madeira-Mamoré, pois essa fazia parte de seu mundo. Em Jirau, ainda é possível ver alguns dos trilhos, assim como as casas antigas que provavelmente davam suporte ao funcionamento do trem e uma caixa d'água que atendia o transporte ferroviário, mas o sentido e os significados não são os mesmos para esses migrantes.

Estas características emergem como fator necessário à reterritorialização da comunidade migrante, posto que

As cidades ribeirinhas, dessa forma, têm fortes enraizamentos, fortes ligações socioeconômicas e culturais com a escala geográfica local e regional; enraizamentos estes que traduzem estreita relação com o rio, não simplesmente pela localização absoluta, devido ao fato de estarem à beira do rio, mas, e principalmente, por apresentarem uma interação funcional com esse elemento natural. São exemplos disso, a circulação fluvial, de subsistência material (fonte de recursos alimentares, uso doméstico etc.), a utilização lúdica (uso do rio para o lazer) e simbólica (a importância do rio no imaginário sociocultural). (TRINDADE JÚNIOR, 2010, p.118).

O topônimo Jirau refere-se à cachoeira de Jirau, onde inicialmente seria construída a UHE. Posteriormente o projeto foi modificado, sem novos estudos ou audiências públicas, mas a cachoeira ficou submersa pela barragem da usina.

Para chegarmos a Jirau é necessário percorrer uma pequena descida no acostamento da BR 364. Ali se encontra "Restaurante da T.", que pertence a uma senhora idosa, que, no entanto, era proprietária de outro estabelecimento comercial do gênero localizado na entrada do Distrito de Mutum-Paraná, agora desterritorializado. Sua opção em mudar-se para Jirau decorreu em razão do espaço destinado ao estabelecimento de seu ponto comercial em Nova Mutum, como compensação pela perda do restaurante, não ser adequado a seus negócios, conforme sua afirmação: "[...] lá no Mutum eu vendia de 4, 5 mil por dia. Parece até mentira falar uma coisa dessa, mas era verdade. Porque era parada de ônibus, os ônibus de turismo tudo parava lá! E agora tá horrível. Eu tinha 13 empregados. Agora eu só tenho uma cozinheira e uma pessoa pra lavar a louça [...]." (Dona T., 2012).

O remanejamento para Nova Mutum, não atendeu Dona T., na medida em que não houve condições de reestruturar suas relações produtivas naquele território. Isto a levou a reassentar-se por conta própria na localidade Jirau, sem nenhum acompanhamento do consórcio ESBR, ou do Estado. Em Mutum-Paraná, seu restaurante funcionava também como parada rodoviária, inclusive com a venda de passagens para a empresa de ônibus que atendia às comunidades da região. 
Em Jirau a estrada encontra-se elevada, devido ao lago formado pela UHE e não foi construído acostamento para os veículos, isso impede que seu restaurante funcione como parada, o que resultou em perdas significativas nos ganhos para sustentar sua família, visto que a maioria dos clientes do restaurante era de passageiros dos ônibus do trajeto entre Guajará-Mirim e Porto Velho.

Além das perdas econômicas, o que se percebe nas falas de Dona T. é o processo de desmantelamento social pelo que passam os remanejados, pois até as relações de confiança entre as pessoas foram abaladas devido ao diálogo fragmentado que ocorreu entre consórcio e os atingidos: "[...] O pessoal da Usina sabe que eu estou aqui. Pois é, o negócio não é fácil, não. Ainda tem mais uma: os meus funcionários não ganharam nada porque muitos, quando eles iam anotar o nome das pessoas, perguntaram pra mim e eu sem ter orientação, sem nada. Perguntaram quantas pessoas tem aqui? Eu disse somos 3 funcionários. Mas eu não sabia que já era pra ver. Porque os meus funcionários tinham quarto. Todos tinham um quartinho pra ele e não ganharam nada. E os meus netos, são meus funcionários porque eu pago pra eles. E também não ganharam nada porque entraram como composição de família. Bateram foto e tudo, não orientaram a gente na hora de fazer o cadastro. Meus funcionários não ganharam nada [...]." (Dona T., 2012).

Com essa situação criada, as relações entre T. e seus funcionários que se baseavam em segurança e confiabilidade, se dissolveram e atualmente a senhora conta com um número mínimo de empregados, apenas para a manutenção do restaurante que tem muito pouco movimento: "[...] A vida da gente tá péssima. Hoje até que tem umas pessoas almoçando, mas tem dias de eu não vender nem um prato de comida. Chega a me dar desgosto [...]." (T., 2012).

Muitas famílias escolheram Jirau por algumas características do território que se assemelham ao antigo Distrito de Mutum-Paraná. Em Mutum era possível pescar e colher as frutas e legumes dos quintais, garantindo assim a subsistência e podendo mesmo destinar uma parte dessa produção para a comercialização. Sobre isso, a Dona T. pondera sobre a atração que a localidade de Jirau está exercendo no momento: "[...] Aqui já tem muita gente, tem mais de cem famílias. Tem muitos de Nova-Mutum que vieram pra cá. Porque tinha muita gente que era pobrezinho e eles vivia da pesca, ia pescar. E lá (Nova Mutum)? Daquele lado ali é tudo gente que veio do Mutum [...]." (Dona T., 2012)

A situação se repete com outros moradores, como é o caso de A. e seu esposo, o senhor U., um casal de idosos que eram produtores de mandioca em Mutum-Paraná, e que diante do que aconteceu tiveram que se reterritorializar, reconstruir suas vidas. Esses moradores se empenharam em transformar seu sítio em Jirau em uma moradia compatível com o que tinham antes do remanejamento, mas a indenização que receberam do consórcio ESBR, segundo o casal, não correspondia ao valor de seu terreno e nem da casa construída no Distrito de Mutum-Paraná. Mesmo assim, com o dinheiro procuram recomeçar a vida e o que se pode constatar é uma residência com uma diversidade de árvores frutíferas e outros legumes e verduras. “[...] Banana, tudo que nós tinha lá tem aqui. Só peguei a indenização na marra. Casa não me deram. Porque eles dizem que eu não morava numa casa. Porque eu deixei uma filha minha numa casa e nós moramos no sítio. Mas de qualquer maneira eles entenderam mal, porque a casa era minha. Fui eu que fiz, eu que construí porque que eu não tinha direito. Aí me deram só um dinheiro lá que nem valia [...]." (U., 2012). 
Sua casa é mista e foi construída em madeira e alvenaria, com esforço próprio, sendo que o senhor U. está em tratamento contra um câncer, mas que isso não foi impeditivo para construir uma casa com características semelhantes àquela em que moravam na antiga comunidade.

\section{CONSIDERAÇÕES SOBRE IDENTIDADE, RESISTÊNCIA E RETERRITORIALIZAÇÃO}

Assim como verificado numa pesquisa a respeito de moradores compulsoriamente reassentados em decorrência da construção da barragem de Tucuruí (Pará), no caso das barragens do Madeira uma reterritorialização em oposição à uma desterritorialização, em virtude de um reassentamento inadequado, o que pode se configurar como uma "estratégia de luta pela apropriação material e simbólica do espaço." (ACSELRAD; SILVA, 2011, p. 70).

A ruptura com o território material e simbólico provoca uma série de perdas, igualmente materiais e simbólicas, que não são remediadas pelo atendimento das necessidades de subsistência, pois a perda simbólica faz com que o indivíduo que está passando por esse incômodo se entregue à depressão, cujo sintoma de doença não o encoraja agir e reagir no novo território.

Adicionado aos processos migratórios passados, ainda paira sobre os moradores de Jirau a possibilidade de mais um deslocamento. Há incertezas por parte do Consórcio ESBR a respeito das cotas de alagamento, o que resulta em elucubrações por parte dos atingidos a respeito de mais uma mudança e consequentemente desterritorialização.

A ideia de um novo remanejamento provoca aflição em uma comunidade que está se consolidando. A pressão externa e o remanejamento imposto de construção da barragem produzem incertezas na população, mas ao mesmo tempo para muitos moradores cria-se a perspectiva de resistência aos processos e propicia a reafirmação de identidades frente ao efeito fragmentador engendrado pelo empreendimento hidrelétrico. É nesse estado de pressão que as comunidades se organizam e encontram estratégias de sobrevivência, ainda que com isso tenha que se sacrificar.

As identidades coletivas não consistem, pois, em estados ou "substancias", mas em processos, que dependem da maneira como os agentes sociais são percebidos pelos outros e se referem à maneira como os agentes sociais se auto-representam e se mobilizam. Em decorrência desta forma de luta, ampliam-se as condições de possibilidade para a emergência de novas unidades de mobilização política e elas apresentam um considerável efeito aglutinador. (ALMEIDA, 2010, p.8).

Como narra o senhor U., o esforço para construir a casa é vinculado à forma como ele percebe seu modo de vida, ou seja de sua condição de identidade. A mesma constatação é comum entre outros moradores de Jirau, os quais tivemos contato e que se encontram ameaçados por um novo remanejamento, assim é necessário que criem 
mecanismos capazes de produzir algum tipo de movimento que unifique as lutas desses "auto reassentados" e com isso suas entidades territoriais sejam fortalecidas.

As identidades territoriais são definidas pela relação entre o indivíduo ou comunidade/grupo e o território, em sua forma concreta e simbólica, considerando o espaço como parte fundamental da produção desta identidade. (COSTA, 1999).

A incapacidade de absorver o modo de vida imposto na cidade de Nova Mutum pode gerar a emancipação e a visibilidade dos desafios pelos quais as populações atingidas do Madeira estão passando desde o início da implantação das UHEs Santo Antônio e Jirau. "[...] Eu não sou da cidade. Não acostumo na cidade. Se eu chegar na cidade eu adoeço. É capaz até de eu morrer, porque eu sou acostumado assim. Eu tenho esse quintalzinho aqui, eu tenho uma macaxeira aqui, um quilometro lá. Todo mundo que chega aqui admirou que o que eu fiz. Tem macaxeira lá, tá tão limpinha. Tenho lá do outro lado: tenho macaxeira, tenho milho, tenho banana. Tudo plantado lá. Quando chega aí, todo mundo admirou tem gente aqui novinho, sadio, que cê não acha um pé de macaxeira, uma banana para você comer aqui. Cê não acha um pé de cana. Não sei o que é que esse povo faz em cima da terra? E eu cheguei aqui, eu com poucos dias eu ajeitei. Olha aqui fruteira. Já vai dar a banana. Eu já tirei banana daí. Daqui a uns dias tem ingá, essas outras frutas, laranja e essas coisas assim é cinco anos, seis anos [...]." (U., 2012).

Com a ameaça de um novo remanejamento, que até o momento não é confirmada, a família do senhor $U$. permanece reorganizando as atividades de maneira a viverem em um território semelhante ao que era anterior ao remanejamento. Os necessários ajustes para o conforto da residência, nesse momento tiveram que paralisar pela rotina da incerteza provocada pelos rumores: "[...] Olha aí as plantas: já tem muda em vaso aí. Nós sai daqui como é que nós vamos carregar isso? Poço aí que toda casa minha eu faço poço dentro de casa. Que é pra quando chover, a água não contaminar. Eu ia fazer a boca nesse meio tempo. Aí falaram que nós vamos ter que sair daqui. Nós não vamos gastar mais nada. Pra mim gastar aqui, ainda vou colocar cerâmica. Mas pra fazer isso eu vou gastar uns 4 mil. Eu ia comprar madeira pra cercar aí tudinho. Eu também já não vou porque tem que gastar. Eu não sei se eu vou sair daqui, eu não sei! Olha, vocês tão vendo nós aqui nessa pouca terrinha como nós já temo aqui! Se nós saímos daqui nós temos que ser compensados [...]." (U., 2012).

Pelo que o morador expressa constata-se que se trata no caso de uma verdadeira defesa territorial, a mudança do território conhecido indica diversas possibilidades que antes não eram cogitadas, contudo se a mudança trouxer melhoria econômica e social para a família a "aceitação" é certa. Ali a família poderá em um novo espaço territorial próprio recriar as diversas situações, contudo no caso destes atingidos, são eles que tiveram de buscar com afinco e com sua iniciativa a reordenação de sua vida em Nova Mutum.

Desta forma, fica em aberto o panorama no qual a comunidade de Jirau busca sua dignidade e reconhecimento, consumado o fracasso do processo de remanejamento para o distrito empresarial de Nova Mutum. Deve-se manter a atenção aos desdobramentos da reconstrução da vida desta comunidade por sua própria conta, o que indica flagrante desproteção aos direitos das comunidades tradicionais da Amazônia. 
Deslocamentos compulsórios impostos arbitrariamente, sem devida consulta e envolvimento dos afetados, comprovam que subjetividades e modos de vida singulares não estão sendo considerados no planejamento e na implementação de grandes projetos de infraestruturas da IIRSA e do PAC.

\section{CONSIDERAÇÕES FINAIS}

Ao analisarmos a ação geopolítica brasileira verificamos que a implantação dos projetos de infraestrutura no presente não se difere em muito daqueles realizados no período de exceção democrática (1964-1984), ainda que na atualidade se tente oferecer uma aura de participação por meio das audiências públicas.

O que se constata é que a força do capital e os interesses colocados pelos mais diversos atores políticos e econômicos internos e externos ao país, o que reforça a tese de Santos (2011) sobre a lógica da globalização "perversa para a maioria da humanidade", cuja implicação é a exclusão e a marginalidade.

No caso das UHEs na Amazônia, notadamente em Rondônia, os impactos decorrentes da implantação dos empreendimentos hidrelétricos atingem indistintamente todos seus habitantes, visto que o Estado se constitui como provedor da geração elétrica, enquanto as receitas com a arrecadação dos impostos são destinadas em sua maioria para outras Unidades da Federação (inclusive mais ricas e com melhores infraestruturas).

Merece serem ressaltadas que as populações indígenas e tradicionais (ribeirinhas, pescadores) são aquelas que recebem os maiores impactos sociais, culturais e econômicas, sendo que muitas delas são compelidas a encontrar outras territorialidades distintas das suas, diluindo seus referenciais de vida.

Embora ocorram os processos de (des)reterritorializações que comprometem as identidades, essas se apresentam como movimentos de resistências das populações frente à omissão, o descaso e a indiferença dos poderes estatais. Aliás, o que se constatou no caso da UHE Jirau é que o Estado atende aos interesses de atores econômicos em nome do "progresso", do "crescimento econômico", do "desenvolvimento" em detrito de outros valores fundamentais à vida.

\section{REFERÊNCIAS}

AMARAL, José Januário de Oliveira; ALMEIDA SILVA, Adnilson de; LEANDRO, Ederson Lauri. Migração e colonização na Amazônia brasileira: notas para um debate. In: OLIVEIRA, Valéria; LEANDRO, Ederson Lauri; AMARAL, José Januário de Oliveira (Orgs.). Migração: múltiplos olhares. São Carlos: Pedro \& João Editores/Ed. UFRO, 2011. p.13-36.

ACSELRAD, Henri; SILVA, Maria das Graças da. Rearticulações sociais da terra e do trabalho em áreas de grandes projetos hidrelétricos na Amazônia. O caso de Tucuruí. In: ZHOURI, Andrea. (Org.). As Tensões do lugar: hidrelétricas, sujeitos e licenciamento ambiental. Belo Horizonte: Ed. UFMG, 2011.

ALMEIDA, Alfredo Wagner Berno de; ALMEIDA JÚNIOR, Emmanuel de Almeida (Orgs.). Mobilizações étnicas e transformações sociais no Rio Negro. Manaus: UEA Edições, 2010. 
BOURDIEU, Pierre. O poder simbólico. Lisboa: Difel, 1989.

BUTTIMER, Anne. Aprendendo o dinamismo do mundo vivido. In: CHRISTOFOLETTI, Antônio. (Org.). Perspectivas geográficas. São Paulo: Difel, 1982.

COSTA, Rogério Haesbaert da. Desterritorialização: entre as redes e os aglomerados de exclusão. In: CASTRO, Iná Elias de; GOMES, Paulo César da Costa; CORRÊA, Roberto Lobato. (Org.). Geografia: conceitos e temas. 14.ed. Rio de Janeiro: Bertrand Brasil, 2011. p.165-205.

Identidades territoriais. In: ROSENDAHL, Zeni; CORREAA, Roberto Lobato (Org.). Manifestações da cultura no espaço. Rio de Janeiro: Ed. UERJ, 1999. p. 169-190.

BRUCE, Glauco. A desterritorialização na obra de Deleuze e Guattari. Geographia, v. 4, n. 7, 2002. Disponível em: <http://www.uff.br/geographia/ojs/index.php/geographia/article/viewFile/74/72>. Acesso em: 20 dez. 2013.

FOUCAULT, Michel. História da Sexualidade I: a vontade de saber. Rio de Janeiro: Graal, 1985.

. Vigiar e punir: nascimento da prisão. 20.ed. Petrópolis, RJ: Vozes, 1987.

Microfísica do poder. 25.ed. Rio de Janeiro: Graal, 2012.

HANNIGAN, John. Sociologia Ambiental. Petrópolis, RJ: Vozes, 2009.

JIRAU Notícias. Edição nº 10. Porto Velho: dezembro de 2010 / janeiro de 2011.

LEONEL JÚNIOR, Mauro de Mello. A morte social dos rios. São Paulo: Perspectiva, 1998.

LIMA, Paulo Cesar Vicente de; VASCONCELOS, Vitor Vieira. Impactos Sociais de Hidrelétricas: avaliação dos Planos de Assistência Social - PAS - no Estado de Minas Gerais, Brasil. In: MAIA, Leonardo Castro; CAPELLI, Sílvia; PONTES JÚNIOR, Felício (Orgs.). Hidrelétricas e atuação do Ministério Público na América Latina. Porto Alegre: Letra \& Vida/ Rede Latinoamericana de Ministério Público Ambiental, 2013. p.175-204.

LOVATO FILHO, Cláudio. Um projeto de todos os brasileiros. Disponível em <http://www. odebrechtonline.com.br/materias/01501-01600/1559/>. Acesso em: 20 dez. 2013.

MONTEIRO, Telma. Complexos hidrelétricos do Tapajós e do Juruena: desenvolvimento ou imposição. In: AMARAL, José Januário de Oliveira; LEANDRO, Ederson Lauri (Orgs.). Amazônia e cenários indígenas. São Carlos: Pedro \& João Editores, 2010. p.83-98.

Santo Antônio e Jirau: hidrelétricas malditas. 2012. Disponível em: <http://telmadmonteiro. blogspot.com.br/2012/03/santo-antonio-e-jirau-hidreletricas.html>. Acesso em: 20 dez. 2013.

NOGUEIRA, Ida Clara Guimarães. Segregação socioespacial urbana no entorno de hidrelétrica: produção do espaço em Tucuruí-PA. 2010. Dissertação (Mestrado em Desenvolvimento e Meio Ambiente Urbano) Universidade Federal de Amazonas. Belém, PA.

RODRIGUES, Roberta Menezes. Desvendando formas e conteúdos: o núcleo urbano de Carajás. In: TRINDADE JÚNIOR, Saint-Clair Cordeiro da; ROCHA, Gilberto de Miranda. (Org.) Cidade e empresa na Amazônia: gestão do território e desenvolvimento local. Belém: Paka-Tatu, 2002.

TRINDADE JÚNIOR, Saint-Clair Cordeiro da. Cidades na floresta: os "grandes objetos" como expressões do meio técnico-científico informacional no espaço amazônico. Rev. Inst. Estud. Bras. [online]. n.51, p. 113-150, 2010. Disponível em: <http://www.revistasusp.sibi.usp.br/scielo.php?pid=S002038742010000200006\&script=sci_arttext>. Acesso em: 01 dez. 2013.

RAFFESTIN, Claude. Por uma geografia do poder. São Paulo: Ática, 1993.

SANTOS, Milton. A Responsabilidade Social do Geógrafo. In: Território Livre. UPEGE/ USP, 1978. p.4149. Disponível em <http:// miltonsantos.com.br/site/de-milton-santos/> Acesso em: 01 dez. 2013.

1996.

. Técnica Espaço Tempo Globalização e meio técnico-cientifico informacional. São Paulo: HUCITEC,

Espaço e Método. São Paulo: Nobel, 1997. 
As cidadanias mutiladas. In: LERNER, Júlio. O preconceito. São Paulo: Imprensa Oficial do Estado, 1997. p.133-144. Disponível em: <http://miltonsantos.com.br/site/de-milton-santos> Acesso em: 01 dez. 2013.

Por uma outra globalização: do pensamento único à consciência universal. 20. ed. Rio de Janeiro: Record, 2011.

SHIVA, Vandana. Recursos Naturais. In: SACHS, Wolfgang (Ed.). Dicionário do desenvolvimento: guia para o conhecimento como poder. Petrópolis, RJ: Vozes, 2000.

SILVA, Jeane Medeiros. Análise do discurso e pesquisa qualitativa na Geografia. In: PESSÔA, Vera Lúcia Salazar, RAMIRES, Cesar de Lima (Org.). Geografia e pesquisa qualitativa: nas trilhas da investigação. Uberlândia: Assis, 2009.

SOUSA, Wanderley Lemgruber. Impacto ambiental de hidrelétricas: uma análise comparativa de duas abordagens. 2000. Dissertação (Mestrado em Planejamento Energético) - COPPE/UFRJ. Rio de Janeiro, RJ. WEBER, Max. Conceitos básicos de sociologia. São Paulo: Centauro, 2002.

Recebido para Avaliação em 11-04-2014

Aceito para publicação em 17-03-2015 